\title{
Comparison of adrenergic agonists for the treatment of ventricular fibrillation and pulseless electrical activity
}

\author{
Barry E. Bleske*, John E. Billi \\ College of Pharmacy, University of Michigan, Ann Arbor, MI 48109-1065, USA
}

Received 21 March 1994; accepted 1 August 1994

\begin{abstract}
The primary role of epinephrine for the treatment of ventricular fibrillation (VF) and pulseless electrical activity (PEA) is to increase blood flow to the myocardium and central nervous system and ultimately improve survival. However, despite the administration of epinephrine, survival following VF or PEA is low. In an attempt to improve outcome from VF and PEA, alternative adrenergic agonists (methoxamine, phenylephrine, norepinephrine) which have different pharmacological properties than epinephrine have been evaluated. In order to determine the role of alternative adrenergic agonists for the treatment of VF and PEA this paper will compare the pharmacological properties and pharmacodynamic effects of these drugs to epinephrine. Specifically, receptor physiology along with the effects of adrenergic agonists on coronary perfusion pressure, survival, myocardial oxygen demand, and cerebral blood flow will be discussed.
\end{abstract}

Keywords: Resuscitation; Epinephrine; Methoxamine; Phenylephrine; Norepinephrine; Ventricular fibrillation; Pulseless electrical activity

\section{Introduction}

According to standard Advanced Cardiac Life Support (ACLS) guidelines epinephrine is considered a first line drug in the treatment of ventricular fibrillation and pulseless electrical activity (PEA) [1]. Because of its adrenergic properties, epinephrine is widely used during cardiac arrests. However, the outcome of patients experiencing ventricular fibrillation or PEA remains poor despite treatment with epinephrine [2,3]. One attempt to improve outcome from a cardiac arrest is to determine if other drugs with adrenergic proper-

\footnotetext{
* Corresponding author.
}

ties (methoxamine, phenylephrine, norepinephrine) may be more effective than epinephrine. Theoretically, pharmacological differences among vasoactive drugs may result in differences in outcome from cardiac arrest. This paper will evaluate the differences among adrenergic drugs in regards to pharmacological properties and efficacy in the treatment of ventricular fibrillation and PEA.

\section{Adrenergic physiology and properties}

The adrenergic system consists of two distinct receptor types, $\alpha$ - and $\beta$-adrenoreceptors. These receptors can be further subclassified as $\alpha_{1}-, \alpha_{2}$, $\beta_{1-}$, and $\beta_{2}$-adrenoreceptors (Table 1). Adrenergic 
Table 1

Peripheral effects mediated by adrenergic receptors

\begin{tabular}{ll}
\hline Receptor & Effect \\
\hline$\alpha_{1}$ & Vasoconstriction \\
& Positive inotropy \\
$\alpha_{2}$ & Vasoconstriction \\
$\beta_{1}$ & Positive inotropy \\
$\beta_{2}$ & Positive chronotropy \\
\hline
\end{tabular}

receptors are located throughout the body with the peripheral and cardiac adrenergic receptors being the most important during ventricular fibrillation and PEA due to the ability to increase systemic and cornary perfusion pressures [4]. $\alpha_{1^{-}}$ Adrenoreceptors are located postsynaptically while $\alpha_{2}$-receptors appear to be located both presynaptically and postsynaptically [4-6]. The effect of postsynaptic $\alpha_{1}$ - and $\alpha_{2}$-receptor stimulation in smooth muscle is excitatory and mediates vasoconstriction [4-6]. Stimulation of presynaptic $\alpha_{2}$-receptors inhibits the neural release of norepinephrine through feedback inhibition [6]. The effects of $\beta_{1}$ stimulation include increases in myocardial contractility and heart rate whereas the stimulation of $\beta_{2}$-receptors results in vasodilation of vascular smooth muscle [6].

The degree of stimulation of $\alpha$ - and $\beta$-receptors by adrenergic agonists during a cardiac arrest is important since coronary perfusion pressure and aortic diastolic pressures are major determinants of successful resuscitation [7-9]. Perfusion of the coronary arteries occurs during the relaxation phase of external chest compressions during cardiopulmonary resuscitation (CPR) and is represented by coronary perfusion pressure [10]. Coronary perfusion pressure is defined as the difference between aortic diastolic and right atrial diastolic pressures [8,11]. Since right atrial diastolic pressure does not vary greatly during CPR, aortic diastolic pressures may also represent myocardial blood flow as well as being an indicator of the ability to resuscitate. Adrenergic agonists are administered during CPR to increase aortic diastolic pressure, coronary perfusion pressure and thus resuscitation. Adrenergic agonists improve aortic and coronary perfusion pressures along with myocardial and cerebral blood flow due to stimulation of $\alpha$-receptors. This results in vasoconstriction of smooth muscles, increases in perfusion pressures, and prevention of arterial collapse, which otherwise may occur secondary to high intrathoracic pressures generated during CPR [6,12-14].

In addition to epinephrine, other adrenergic agonists have been used during ventricular fibrillation and PEA, including norepinephrine, phenylephrine, and methoxamine. There are a number of differences among these adrenergic agonists including $\alpha$ - and $\beta$-receptor activity (Table 2). Epinephrine is considered to be a mixed $\alpha$ and $\beta$-agonist with $\alpha_{1}, \alpha_{2}, \beta_{1}$, and $\beta_{2}$ properties $[6,15]$. Norepinephrine agonist properties are similar to those of epinephrine except that the $\beta_{2}$ adrenergic activity of norepinephrine is negligible compared to epinephrine [6]. Phenylephrine and methoxamine are considered selective $\alpha_{1}$-agonists with minimal $\alpha_{2}, \beta_{1}$, or $\beta_{2}$ adrenergic properties $[6,15]$.

Differences in receptor stimulation between the adrenergic agonists may have theoretical advantages and disadvantages during CPR. It is known that $\alpha$ adrenergic properties are required for peripheral vasoconstriction which leads to increased coronary perfusion pressure and potential improved survival. However, there may be differences in the ability of $\alpha_{1}$ - and $\alpha_{2}$-receptors to cause vasoconstriction. There is evidence to suggest that stimulation of $\alpha_{2}$-receptors by drug therapy may be more important in causing vasoconstriction than $\alpha_{1}$-receptor stimulation $[16,17]$. One potential explanation for differences between these receptors is that $\alpha_{2}$-receptors are

Table 2

Adrenergic agonists

\begin{tabular}{ll}
\hline Drug & Receptors \\
\hline Epinephrine & $\alpha_{1}, \alpha_{2}, \beta_{1}, \beta_{2}$ \\
Norepinephrine & $\alpha_{1}, \alpha_{2}, \beta_{1}$, \\
Methoxamine & $\alpha_{1}$ \\
Phenylephrine & $\alpha_{1}$ \\
\hline
\end{tabular}


located extrajunctionally along the intima of the vessel walls and may be more accessible than $\alpha_{1}$-receptors to the effects of circulating catecholamines especially in ischemic states due to their location $[4,16,18,19]$. Because of the location of $\alpha_{2}$-receptors, drugs which stimulate $\alpha_{2}-$ receptors may result in more vasoconstriction than drugs that stimulate only $\alpha_{1}$-receptors. Differences in $\alpha_{1}$ - and $\alpha_{2}$-receptor density during ischemia is another explanation for the potential increased importance of $\alpha_{2}$-receptors during CPR. It has been hypothesized that during ischemia there may be a down-regulation of $\alpha_{1}$-receptors with an increase in $\alpha_{2}$-receptors (or binding sites) [20-22]. However, it should be emphasized that this hypothesis is based in part on a study that demonstrated an increase in $\alpha_{2}$-binding sites in rat vas deferens [21]. It is unknown if this same effect occurs in humans during CPR.

Beta adrenergic receptor stimulation without concurrent $\alpha$ adrenergic stimulation during CPR has been shown not to improve survival, probably due to vasodilation of the peripheral circulation [12]. However, the combination of $\alpha$ and $\beta$ properties may be beneficial. Alpha receptor stimulation will result in peripheral vasoconstriction (as previously discussed), while $\beta$ adrenergic stimulation may improve cerebral blood flow by vasodilating the cerebral vasculature and may also decrease the energy needed for defibrillation [23-26]. Despite the potential benefit with combination of $\alpha$ and $\beta$ properties there is still a concern about $\beta$ adrenergic effects during CPR. This concern includes not only the peripheral vasodilation that may occur with $\beta_{2}$ stimulation but also the potential effect of increasing myocardial oxygen demand and decreasing high energy phosphates secondary to $\beta_{1}$ stimulation.

Briefly, high energy phosphates which includes but not limited to adenosine triphosphate (ATP), adenosine diphosphate, and phosphocreatine are important in that they provide the necessary energy for myocardial function. During ventricular fibrillation high energy phosphates are decreased $[27,28]$. It is hypothesized that if high energy phosphates are decreased beyond a critical point, resuscitation is not possible. Theoretically, a potential concern with adrenergic agonists with $\beta_{1}$ properties is that myocardial energy requirements and oxygen demands may be increased to a greater extent than which myocardial oxygen can be delivered. This may result in further decrease in high energy phosphates and a limited ability to resuscitate a patient. Whether or not this occurs is not certain. One study compared myocardial ATP concentrations between 10 dogs receiving epinephrine ( $1 \mathrm{mg}$ bolus followed by $0.2 \mathrm{mg} / \mathrm{min}$ ) to 10 controlled dogs undergoing CPR [29]. The results demonstrated that myocardial ATP concentrations decreased significantly from baseline but the decrease was comparable between the two groups. In a different study, standard dose epinephrine $(0.02 \mathrm{mg} / \mathrm{kg})$ was compared to high dose epinephrine $(0.2 \mathrm{mg} / \mathrm{kg})$ in swine undergoing CPR on myocardial high energy phosphates [30]. This study demonstrated a significant increase in coronary perfusion pressure and phosphocreatine for the high dose epinephrine group as compared to standard dose epinephrine group. This study suggests that high dose epinephrine may help improve myocardial energy stores in part due to increasing myocardial blood flow (i.e. coronary perfusion pressure) and potentially the myocardial oxygen delivery to demand ratio. Another study in dogs undergoing CPR, suggests that by blocking $\beta$-receptors with propranolol and administering phenylephrine that ATP concentrations can be significantly improved compared to control [31]. These results may be due to the fact that the combination of phenylephrine and propranolol appeared to have the greatest effect on coronary perfusion pressure. However, it should be noted that there was no difference between this group and the epinephrine treatment group in regards to ATP concentrations, although the phenylephrine and propranolol group did have higher ATP concentrations $(29.5 \pm 3$ vs. $19.2 \pm 1.6 \mathrm{nmol} / \mathrm{mg}$ of protein). Overall then, the $\beta_{1}$ effects of adrenergic agonists on myocardial oxygen demand and high energy phosphates may be negligible if oxygen delivery can be increased to exceed oxygen demand. With additional studies, $\beta$-blockers may also be proven to be beneficial during CPR in regards to improving high energy phosphate levels. However, more studies are needed to clearly delineate the $\beta_{1}$ effects of adrenergic agonists during CPR. A more 
complete review of high energy phosphates may be found elsewhere [32].

In discussing receptor physiology and the effect of adrenergic agonist the role of adenosine needs to be mentioned. Adenosine receptors are located in the myocardium and vascular system. Adenosine receptors may be classified as $\mathrm{Al}$ and $\mathrm{A} 2$ receptors [33-35]. A1 receptors are located on the myocardium and $A 2$ receptors on vascular smooth muscle. Stimulation of Al receptors results in negative chronotropic and dromotropic actions. A2 receptor stimulation results in vasodilation of the coronary arteries. The exact mechanism by which adenosine causes vasodilation is unknown, but appears to invoke, in part, endothelium.

The role of adenosine during CPR has not been completely elucidated, however, data from other ischemic and reperfusion models suggest an important role. This role may include coronary vasodilation (with improvement of coronary blood flow), decrease inotropic effect secondary to $\beta_{1}$ stimulation (may decrease oxygen demand and preserve high energy phosphates), preserve myocardial function post ischemic event, inhibit neutrophil activation and free radical generation [36-40]. The importance of the vasodilating action of adenosine during CPR was suggested in a recent study [41]. In this study, adenosine $(100 \mu \mathrm{g} / \mathrm{kg}$ per min) was administered to rats undergoing CPR. The results demonstrated similar survival between the adenosine and control groups (6/7 vs. $4 / 7$ for adenosine and control animals, respectively). However, what was most interesting was that the coronary perfusion pressure was significantly lower in the adenosine group as compared to the control group ( $7 \pm 2$ vs. $22 \pm 3 \mathrm{mmHg} ; P<0.01$, respectively) and yet survival was similar. Based on these findings, the authors suggest that adenosine induced vasodilation may increase coronary reserve which may result in increase coronary blood flow despite low coronary perfusion pressure.

Another important aspect in regards to adenosine and CPR therapy is that adrenergic agonists may play a role in the regulation of endogenous adenosine. It has been shown that $\alpha_{1}$ adrenergic stimulation during ischemia may enhance adenosine release and that $\alpha_{2}$ adrenergic stimulation modifies the vasodilatory action of adenosine [42-45]. These findings have lead to the hypothesis that $\alpha_{1}$ and $\alpha_{2}$ adrenergic stimulation during ischemia may play an important role in the effects of adenosine. If this hypothesis is true, then adrenergic therapy during CPR may have a greater role then just causing vasoconstriction. This hypothesis also suggests that a pure $\alpha_{1}$ - or $\alpha_{2}$-agonist may not be as beneficial during CPR as mixed $\alpha_{1}$ - and $\alpha_{2}$-agonists.

\section{Ventricular fibrillation}

\subsection{Coronary perfusion pressure and survival}

The results of studies evaluating adrenergic agonists in animal models are shown in Table 3 . In comparing the effects of intravenous phenylephrine to epinephrine, earlier studies suggested that these agents had similar effects on survival [46-48]. In another study in dogs intravenous phenylephrine $(0.4 \mathrm{mg} / \mathrm{kg}$ bolus at the onset of CPR and 5 min after) was compared to intravenous epinephrine $(0.2 \mathrm{mg} / \mathrm{kg}$ bolus at the onset of CPR and $5 \mathrm{~min}$ after) and to phenylephrine plus propranolol (1 mg/kg at the onset of CPR) [31]. For the experimental protocol ventricular fibrillation was induced followed immediately by CPR, each treatment group described above and a control group evaluated six dogs each. From the results reported it appears that after the first bolus dose of drug there was a similar increase in coronary perfusion pressure. However, after the 5-min time point the phenylephrine plus propranolol group appeared to have a higher pressure response and was able to sustain this response over time. Unfortunately, actual values were not reported and it appears that the differences was not statistically significant despite the apparent visual differences. The authors suggested that the reason for the better response to the phenylephrine and propranolol group was due to propranolol's ability to block $\beta$-receptors and allowing for unopposed $\alpha$ adrenergic stimulation. They also suggested that $\beta$ blockade may increase coronary flow by decreasing the force of ventricular fibrillation. However, a different study in pigs with rigorous evaluation of coronary perfusion pressure and 
Table 3

Animal CPR models

\begin{tabular}{|c|c|c|c|c|c|c|c|c|c|c|c|}
\hline Ref. & $\begin{array}{l}\text { VF } \\
\text { (min) }\end{array}$ & $\begin{array}{l}\text { CPR } \\
(\mathrm{min})\end{array}$ & Drug & Dose $^{a}$ & Model & $N$ & $\mathrm{CPP}_{\mathrm{B}}$ & $\mathrm{CPP}_{\mathrm{P}}$ & $\mathbf{M B F}_{\mathbf{B}}$ & $\mathrm{MBF}_{\mathbf{P}}$ & Survival \\
\hline \multirow[t]{4}{*}{ [16] } & 10 & 6.5 & $\mathbf{E}$ & 0.2 & Pig & 5 & $2.3 \pm 3.3$ & $40.3 \pm 4.1$ & $5.4 \pm 2.5$ & $117.7 \pm 58.3^{*}$ & $4 / 5$ \\
\hline & & & $\mathbf{M}$ & 0.1 & Pig & 5 & $24.8 \pm 6.8$ & $24.4 \pm 6.2$ & $3.3 \pm 2.6$ & $14.8 \pm 30.4$ & $1 / 5$ \\
\hline & & & & 1.0 & Pig & 5 & $13 \pm 5.3$ & $13 \pm 11.5$ & $4.7 \pm 5.9$ & $9.1 \pm 9.9$ & $0 / 5$ \\
\hline & & & & 10.0 & Pig & 5 & $16 \pm 6.9$ & $14 \pm 6.2$ & $8.8 \pm 8.9$ & $20.6 \pm 11.2$ & $0 / 5$ \\
\hline \multirow[t]{3}{*}{ [17] } & 10 & 6.5 & $\mathbf{E}$ & 0.2 & Pig & 5 & $9.2 \pm 12.4$ & $42.6 \pm 5.3$ & $5.2 \pm 3.4$ & $67.2 \pm 49.4^{\circ}$ & $4 / 5$ \\
\hline & & & $\mathbf{P}$ & 0.1 & Pig & 5 & $12.4 \pm 8.9$ & $10.3 \pm 10$ & $6.6 \pm 7.6$ & $7.0 \pm 7.1$ & $0 / 5$ \\
\hline & & & $\mathbf{P}$ & 1 & Pig & 5 & $23.5 \pm 13.6$ & $14.8 \pm 19.6$ & $13.3 \pm 20$ & $36.7 \pm 21.1$ & $0 / 5$ \\
\hline \multirow[t]{4}{*}{ [20] } & 10 & 6.5 & $\mathbf{E}$ & 0.2 & Pig & 5 & $9.2 \pm 12.4$ & $42.6 \pm 5.3^{* * *}$ & $5.2 \pm 3.4$ & $69.1 \pm 53.1$ & $4 / 5$ \\
\hline & & & $\mathbf{N}$ & 0.08 & Pig & 5 & $4.2 \pm 6.5$ & $18.8 \pm 9.8$ & $3.1 \pm 2.1$ & $35.5 \pm 39$ & $2 / 15$ \\
\hline & & & $\mathbf{N}$ & 0.12 & Pig & 5 & $9.2 \pm 5.2$ & $48.4 \pm 8.6^{* *}$ & $11.7 \pm 12$ & $94.5 \pm 15.4$ & $5 / 5$ \\
\hline & & & $\mathbf{N}$ & 0.16 & Pig & 5 & $4.6 \pm 9.9$ & $34.4 \pm 18.8^{* *}$ & $51.3 \pm 3$ & $100.7 \pm 77.3$ & $5 / 5$ \\
\hline \multirow[t]{3}{*}{ [46] } & 10 & 4 & $\mathbf{E}$ & 1 & Dog & 15 & & & & & $7 / 15$ \\
\hline & & & $\mathbf{P}$ & 10 & Dog & 15 & & & & & $10 / 15$ \\
\hline & & & $\mathbf{M}$ & 20 & Dog & 15 & & & & & $13 / 15$ \\
\hline \multirow[t]{3}{*}{ [47] } & & 5 & $\mathrm{E}$ & 1 & Dog & 13 & & 32 & & & $11 / 13$ \\
\hline & & & $\mathbf{P}$ & 10 & Dog & 9 & & 33 & & & $9 / 9$ \\
\hline & & & $\mathbf{M}$ & 20 & Dog & 12 & & 45 & & & $12 / 12$ \\
\hline \multirow[t]{2}{*}{ [47] } & & 10 & $\mathrm{E}$ & 1 & Dog & 10 & & 35 & & & $8 / 10$ \\
\hline & & & $\mathbf{P}$ & 10 & Dog & 9 & & 44 & & & $8 / 9$ \\
\hline \multirow[t]{2}{*}{ [48] } & 9 & 3 & $\mathbf{E}$ & 1 & Dog & 10 & & & & & $8 / 10$ \\
\hline & & & $\mathbf{P}$ & 10 & Dog & 8 & & & & & $6 / 8$ \\
\hline \multirow[t]{4}{*}{ [55] } & 1 & 25 & $\mathbf{E}$ & $\begin{array}{c}0.02 \\
3 \mathrm{~min}\end{array}$ & Dog & 6 & & & & $25 \pm 15$ & $1 / 6$ \\
\hline & & & & 0.2 & Dog & 6 & & & & $24.3 \pm 10.7$ & $1 / 6$ \\
\hline & & & & $3 \mathrm{~min}$ & & & & & & & \\
\hline & & & $\mathbf{M}$ & 20 & Dog & 6 & & & & $30.8 \pm 7.4$ & $6 / 6 \dagger$ \\
\hline \multirow[t]{2}{*}{ [56] } & 3 & 10 & $\mathbf{E}$ & 0.05 & Dog & 6 & & $19.2 \pm 7.8$ & & & $5 / 6$ \\
\hline & & & $\mathbf{M}$ & 2 & Dog & 6 & & $20.0 \pm 6.0$ & & & $5 / 6$ \\
\hline \multirow[t]{2}{*}{ [57] } & 4 & 1 & $\mathbf{E}$ & 45 & Pig & 7 & & $32 \pm 8$ & & & $6 / 7$ \\
\hline & 4 & 1 & $\mathbf{N}$ & 45 & Pig & 7 & & $30 \pm 6$ & & & $7 / 7$ \\
\hline \multirow[t]{2}{*}{ [58] } & 10 & 6.5 & $\mathbf{E}$ & 0.2 & Pig & 7 & $6.1 \pm 11.4$ & $40.0 \pm 6.3$ & $5.1 \pm 3.0$ & $62.2 \pm 45.3$ & $6 / 7$ \\
\hline & & & $\mathbf{N}$ & 0.2 & Pig & 7 & $6.8 \pm 9.1$ & $25.9 \pm 13.5$ & $3.0 \pm 2.5$ & $118.9 \pm 73.1 \ddagger$ & $4 / 7$ \\
\hline \multirow[t]{2}{*}{ [59] } & $?$ & 8 & $\mathbf{E}$ & 45 & Pig & 7 & & & $71 \pm 10$ & $126 \pm 18$ & $3 / 7$ \\
\hline & & & $\mathbf{N}$ & 45 & Pig & 7 & & & $74 \pm 11$ & $107 \pm 30$ & $7 / 7$ \\
\hline
\end{tabular}

VF, ventricular fibrillation; $C P R$, cardiopulmonary resuscitation; $\mathrm{CPP}_{\mathrm{B}}$, coronary perfusion pressure baseline (mmHg); $\mathrm{CPP}_{\mathrm{P}}$, coronary perfusion pressure post-drug administration; $\mathbf{M B F}_{\mathrm{B}}$, myocardial blood flow baseline (ml/min per $100 \mathrm{~g}$ ); $\mathbf{M B F _ { \mathrm { P } }}$, myocardial blood flow post-drug administration; $E$, epinephrine; $P$, phenylephrine; $M$, methoxamine; $N$, norepinephrine.

${ }^{a}$ Values in bold type are $\mathrm{mg} / \mathrm{kg}$; values in normal type are $\mathrm{mg}$; values in italic type are $\mu \mathrm{g} / \mathrm{kg}$.

${ }^{*} P<0.05$, compared to methoxamine.

$* * P<0.05$, compared to $0.08 \mathrm{mg} / \mathrm{kg} \mathrm{NE}$.

$\dagger P<0.01$, compared to epinephrine.

$\ddagger P=0.04$, compared to epinephrine.

${ }^{\circ}$ Epinephrine $0.2 \mathrm{mg} / \mathrm{kg}$ and phenylephrine $1.0 \mathrm{mg} / \mathrm{kg}$ were significantly better $(P=0.009)$ than phenylephrine $0.1 \mathrm{mg} / \mathrm{kg}$.

myocardial blood flow suggests that epinephrine is more effective than phenylephrine [17]. In this study, equivalent pressor doses of phenylephrine was stated to be approximately five times that of epinephrine $(1 \mathrm{mg} / \mathrm{kg}$ vs. $0.2 \mathrm{mg} / \mathrm{kg}$ for phenylephrine and epinephrine, respectively). In another study by the same author with similar design as the previous study, intravenous epinephrine $(0.2 \mathrm{mg} / \mathrm{kg})$ was compared to intravenous phenylephrine $(1.0 \mathrm{mg} / \mathrm{kg}$ and $10 \mathrm{mg} / \mathrm{kg})$ in 
swine ( $n=5$ for each group) [49]. Although, no coronary perfusion pressure values were reported, aortic diastolic pressure values were. For the epinephrine group, aortic diastolic pressures increased from $9 \pm 8$ to $31 \pm 23 \mathrm{mmHg}$ (pre- to post-drug), for the $1.0 \mathrm{mg} / \mathrm{kg}$ phenylephrine group pressure changed from $26 \pm 13$ to $25 \pm 12$ $\mathrm{mmHg}$, and for the $10 \mathrm{mg} / \mathrm{kg}$ phenylephrine group pressure increased from $19 \pm 12$ to $36 \pm 22$ $\mathrm{mmHg}$. There was no significant differences between the groups despite the greater increase in the epinephrine group. Similar results were seen in an earlier study by the same author [50]. In this study in which the study design was similar to the previous study, intravenous epinephrine $0.2 \mathrm{mg} / \mathrm{kg}$ was compared to intravenous phenylephrine 0.1 $\mathrm{mg} / \mathrm{kg}$. The results demonstrated that there was an increase in aortic diastolic pressure (no coronary perfusion pressure values were reported) following epinephrine therapy $(18.5 \pm 4.9$ to $31 \pm 19.1$ $\mathrm{mmHg}$ ) whereas there was a decrease following phenylephrine therapy $(19.4 \pm 8.3$ to $14.6 \pm 7.7$ $\mathrm{mmHg}$ ). Overall it appears that phenylephrine may increase pressures in high enough doses but it is questionable whether or not it has similar magnitude of response as epinephrine. Differences in animal species and study design may account for the differences seen between studies. Specifically, for study design, differences in dose of drug used, the time in ventricular fibrillation, the time when CPR was started and stopped, time drug was administered, and pressure measurements (earlier studies pressure changes were not reported or controlled for at baseline) may all effect the results of a study. For example, the longer an animal is in ventricular fibrillation and undergoing CPR the less likely they are to response to drug therapy or to survive. In regards to the use of different species of animals, differences in the physiology of the heart (swine appear to have coronary circulation, collateral circulation, and conduction system more similar to humans than canines do) along with receptor distribution between species may alter the response to drug therapy [51-54]. These differences make if difficult to compare studies across different species.

A study by Brown et al. in pigs showed that high dose epinephrine $(0.2 \mathrm{mg} / \mathrm{kg})$ resulted in a greater increase in coronary perfusion pressure and myocardial blood flow $(P<0.05)$ as compared to three different doses of intravenous methoxamine [16]. There was also a trend demonstrating improved survival in the epinephrine group. In contrast, a study in dogs showed that methoxamine significantly improved survival $(P<0.01)$ compared to epinephrine following a prolonged CPR period, despite similar increases in blood flow to the left ventricle [55]. The differences in survival may be accounted for by the finding that aortic diastolic pressures were significantly higher at 15 and $20 \mathrm{~min}$ after the start of ventricular fibrillation for the methoxamine group. Other animal studies demonstrated similar survival between methoxamine and epinephrine $[46,47,56]$. Unfortunately, there is limited information regarding coronary perfusion pressure and myocardial blood flow given in these studies. Overall, positive results for both methoxamine and epinephrine were seen, differences in protocol design and resuscitation techniques make comparisons among studies difficult. It is interesting to note that positive results for methoxamine occurred in the dog models and not in the pig models, suggesting interspecies differences. Interspecies differences includes as mention above myocardial physiology and receptor density. In regards to receptor differences, one study showed that in isolated arteries, greyhound arteries had a greater response than pig arteries to norepinephrine [54]. This suggest differences in receptor density and may account for differences seen between swine and canine models.

Four recent studies have compared epinephrine to norepinephrine in pigs [20,57-59]. One dose ranging study demonstrated similar effects between high dose epinephrine $(0.2 \mathrm{mg} / \mathrm{kg})$ and norepinephrine doses of $0.12 \mathrm{mg} / \mathrm{kg}$ and 0.16 $\mathrm{mg} / \mathrm{kg}$ on coronary perfusion pressure and myocardial blood flow [20]. Similar effects were also seen with the same dose $(0.045 \mathrm{mg} / \mathrm{kg})$ of epinephrine and norepinephrine in two other studies [57,59]. In a fourth study, $0.2 \mathrm{mg} / \mathrm{kg}$ of norepinephrine significantly improved $(P=0.04)$ myocardial blood flow compared to $0.2 \mathrm{mg} / \mathrm{kg}$ of epinephrine; however, epinephrine tended to increase coronary perfusion pressure to a greater extent [58]. There appeared to be no difference in 
survival between the two agents among the studies. Overall, it appears that norepinephrine and epinephrine have similar effects on coronary perfusion pressure, myocardial blood flow, and survival.

\subsection{Myocardial oxygen demand}

One issue that has been raised with the use of epinephrine is its $\beta_{1}$ adrenergic effect on the heart during cardiac arrest. Stimulation of $\beta_{1}$-receptors produces inotropic and chronotropic effects in the normal heart. During ventricular fibrillation, the ability to increase heart rate is probably irrelevant, however, the effect on the force of contraction and cellular metabolism (including decreasing high energy phosphates as previously described) may not be [4]. A number of studies have attempted to evaluate the effects of adrenergic agonists with $\beta_{1}$ adrenergic properties (epinephrine) on myocardial energetics and oxygen demand compared to adrenergic agonists with minimal or no $\beta_{1}$ properties (phenylephrine, methoxamine, norepinephrine) $[16,17,20,56-61]$. Brown et al. (Table 3) compared the effects of epinephrine and phenylephrine on myocardial oxygen delivery, consumption, and myocardial oxygen extraction ratio in pigs [17]. There was a statistically significant increase in myocardial oxygen delivery during CPR post drug delivery for epinephrine $0.2 \mathrm{mg} / \mathrm{kg}$ and phenylephrine $1 \mathrm{mg} / \mathrm{kg}$ compared to phenylephrine $0.1 \mathrm{mg} / \mathrm{kg}(10.6 \pm 7.5$ vs. $5.3 \pm 3.6$ vs. $1.0 \pm 1.2 \mathrm{ml} \mathrm{O} / \mathrm{min}$ per $100 \mathrm{~g}$, respectively). Similarly, myocardial oxygen consumption statistically increased for epinephrine and the higher phenylephrine dose compared to the lower phenylephrine dose $(7.6 \pm 4.4$ vs. $4.8 \pm 3.1$ vs. $1.0 \pm 1.1 \mathrm{ml} \mathrm{O} / \mathrm{min}$ per $100 \mathrm{~g}$, respectively). However, the oxygen extraction ratio was significantly lower with epinephrine compared to both doses of phenylephrine $(76.6 \pm 10.5 \%$ vs. $90.7 \pm 7.5 \%$ vs. $94.6 \pm 4.0 \%$, respectively), which suggests that higher oxygen delivery with epinephrine more than offset higher oxygen consumption. The results from this study suggest that epinephrine improves both the delivery and use of oxygen more so than phenylephrine and that $\beta_{1}$ adrenergic effects may not be deleterious to the balance of oxygen supply and demand. These effects may not be the same in naturally occurring ischemic myocardium because of limits on the ability to increase perfusion, which is usually secondary to coronary stenosis. For example, the effect of coronary stenosis on coronary blood flow was evaluated in a study in swine, in which a $33 \%$ stenosis was induced prior to ventricular fibrillation and closed chest CPR [62]. The results demonstrated that during CPR endocardial blood flow distal to the stenosis was significantly less as compared to blood flow proximal to the stenosis. As suggested by the study, coronary stenosis may limit the ability to increase blood flow following administration of an adrenergic agonist and thus allowing $\beta_{1}$ effects to increase myocardial oxygen demand.

In another study, epinephrine (5 $\mu \mathrm{g} / \mathrm{min})$ or phenylephrine ( $50 \mu \mathrm{g} / \mathrm{min}$ ) was infused for $5 \mathrm{~min}$ during ventricular fibrillation in isolated dog hearts [60]. Coronary blood flow and myocardial oxygen consumption was significantly greater for epinephrine following $4 \mathrm{~min}$ of ventricular fibrillation $(30.9 \pm 11.7 \mathrm{ml} / \mathrm{min}$ per $100 \mathrm{~g}$ and $5.4 \pm 1.9$ $\mathrm{ml} \mathrm{O}_{2} / \mathrm{min}$ per $100 \mathrm{~g}$, respectively) than with phenylephrine $(24.4 \pm 6.0 \mathrm{ml} / \mathrm{min}$ per $100 \mathrm{~g}$ and $3.8 \pm 1.1 \mathrm{ml} \mathrm{O}_{2} / \mathrm{min}$ per $100 \mathrm{~g}$, respectively). In addition, $10 \mathrm{~min}$ after defibrillation, the slope of the end-systolic pressure volume relation was depressed with epinephrine, and increased with phenylephrine $(72 \pm 17 \%$ vs. $143 \pm 17 \%, p<$ 0.002 , respectively). From these results, the authors concluded that left ventricular function declines following epinephrine administration, whereas function is preserved following phenylephrine use. Differences in the results of these studies by Brown et al. and Midei et al. may be accounted for by the different animal species used and the intact versus isolated models evaluated. Specifically, Brown used an intact animal model in which closed chest CPR was performed which probably is more similar to a human CPR setting than an isolated heart model. Another difference between the two models is that coronary perfusion pressure was held constant and rather high $(30 \mathrm{mmHg})$ in the isolated model which probably does not reflect an actual CPR setting. Despite these limitations of an isolated model it 
does provide for precise control of variables such as coronary perfusion pressure and allows for accurate measurements of other variables such as left ventricular function. It is not known which model is the best for determining the metabolic and physiological effects that occur following drug administration in humans.

In comparing epinephrine to methoxamine, Brown et al. (Table 3) demonstrated in pigs that myocardial oxygen delivery was higher for epinephrine versus methoxamine in doses of 0.1 $\mathrm{mg} / \mathrm{kg}, 1.0 \mathrm{mg} / \mathrm{kg}$, and $10 \mathrm{mg} / \mathrm{kg}(20.6 \pm 12.7 \mathrm{vs}$. $5.2 \pm 6.8$ vs. $2.8 \pm 2.9$ vs. $3.4 \pm 0.9 \mathrm{ml} \mathrm{O} 2 / \mathrm{min}$ per $100 \mathrm{~g}$, respectively), as was myocardial oxygen consumption $(15.6 \pm 10.1$ vs. $4.4 \pm 5.8$ vs. $2.6 \pm 2.6$ vs. $3.1 \pm 0.7 \mathrm{ml} \mathrm{O} / \mathrm{min}$ per $100 \mathrm{~g}$, respectively) [16]. He also demonstrated that the oxygen extraction ratio for epinephrine was lower than with methoxamine $(0.8 \pm 0.19$ vs. $0.93 \pm 0.09,0.95 \pm 0.04$ vs. $0.91 \pm 0.04)$. These data suggest that epinephrine improves myocardial oxygen delivery over utilization better than methoxamine. Another study (Table 3) demonstrated in dogs no difference between epinephrine and methoxamine in regards to systemic lactate, myocardial lactate, or myocardial oxygen extraction ratios $(-27 \pm 40$ vs. $-25 \pm 24,-101 \pm 116$ vs. $-120 \pm 64,90 \pm 9$ vs. $86 \pm 61$, respectively) [56]. These data suggest that the $\beta$ adrenergic stimulating properties of epinephrine are not deleterious as compared to methoxamine in this model.

In a third study, methoxamine $0.25 \mathrm{mg} / \mathrm{kg}$ per min or epinephrine $10 \mu \mathrm{g} / \mathrm{kg}$ per min continuous infusion was administered to five dogs on cardiopulmonary bypass following ventricular fibrillation [61]. The results showed that epinephrine may worsen myocardial ischemia by increasing oxygen demands (increasing intraventricular balloon pressure $24 \%$ and oxygen uptake $42 \%$ ) while impeding subendocardial blood supply (endocardial/epicardial flow ratio decreased from 0.79 to 0.48 ). Conversely, methoxamine did not significantly alter these parameters. One explanation for the difference between the results of this and the other two studies is that cardiopulmonary bypass was used to maintain a high coronary perfusion pressure, which may not allow epinephrine or methoxamine to exert their physiological effects.
There are three studies which evaluated norepinephrine and epinephrine. Unlike previous studies with phenylephrine and methoxamine, agents which lack both $\alpha_{2}$ and $\beta_{1}$ and $\beta_{2}$ adrenergic activity, norepinephrine lacks significant $\beta_{2}$ adrenergic properties compared to epinephrine. In the pig model, Robinson et al. (Table 3) showed a trend in which norepinephrine $(0.12 \mathrm{mg} / \mathrm{kg}$ and $0.16 \mathrm{mg} / \mathrm{kg}$ ) improved myocardial oxygen delivery versus epinephrine $(16.7 \pm 3.2$ and $14.8 \pm 9.6$ vs. $10.5 \pm 7.4$, respectively) as well as myocardial oxygen extraction $(69.4 \pm 15.1$ and $65.2 \pm 20$ vs. $76.7 \pm 11$, respectively) [20]. A study evaluating $45 \mu \mathrm{g} / \mathrm{kg}$ of epinephrine and norepinephrine in pigs showed that the myocardial oxygen extraction ratio for norepinephrine was significantly improved compared to epinephrine $(37.3 \pm 9.8 \mathrm{vs}$. $51.5 \pm 13 ; P<0.05$ ) [59]. However, another study evaluating $0.2 \mathrm{mg} / \mathrm{kg}$ of norepinephrine and epinephrine showed no difference in myocardial oxygen extraction ratio $(77 \pm 13.4$ vs. $78.2 \pm 13)$ between the two drugs while norepinephrine resulted in a significant increase in myocardial oxygen delivery $\left(19.9 \pm 13.4 \mathrm{ml} \mathrm{O}_{2} / 100 \mathrm{~g}\right.$ vs. $\left.9.4 \pm 6.3 \mathrm{ml} \mathrm{O}_{2} / 100 \mathrm{~g}\right)$ and consumption $\left(14.2 \pm 7.7\right.$ vs. $\left.7 \pm 3.8 \mathrm{ml} \mathrm{O}_{2} / 100 \mathrm{~g}\right)$ compared to epinephrine [58]. These data suggest that norepinephrine may have similar or more beneficial effects on myocardial oxygen delivery and demand than epinephrine. However, as previously discussed, high dose epinephrine may have beneficical effects on myocardial oxygen delivery as seen by the effects on high energy phosphates [30].

In summary, results from the available studies suggest that the $\beta_{1}$-agonist effects of epinephrine as compared to phenylephrine and methoxamine may either improve or worsen oxygen metabolism during ventricular fibrillation and CPR. There are insufficient data to claim that $\beta_{1}$ adrenergic effects are deleterious. However, as alluded to earlier, negative effects of $\beta_{1}$ stimulation may become apparent when coronary stenosis is present due to diminished blood flow post coronary stenosis. In addition, it is important to realize that with only closed chest CPR there is an inadequate increase in coronary blood flow to meet the myocardial oxygen demands of the heart $[10,63]$. Therefore, any further increase in demand due to $\beta_{1}$ stimula- 
tion without adequate increase in perfusion may be detrimental. In regards to $\beta_{2}$ adrenergic effects of epinephrine, there are data to suggest, although very limited, that agents which lack $\beta_{2}$ effects, such as norepinephrine, may be more beneficial.

\subsection{Cerebral blood flow}

In addition to myocardial hemodynamics, the effects of vasopressors on patient outcome may also relate to cerebral hemodynamics. The effects of epinephrine and phenylephrine on regional cerebral blood flow was evaluated in one study comparing intravenous epinephrine $0.2 \mathrm{mg} / \mathrm{kg}$ and phenylephrine $0.1 \mathrm{mg} / \mathrm{kg}$ in pigs [50]. The design of this study was similar to previous studies performed by Brown et al. (Table 3) [17]. Cerebral blood flow was measured by radionuclide microspheres. There was significantly greater improvement in cerebral blood flow $(P<0.02)$ following epinephrine administration as compared to phenylephrine in all areas of the brain measured (left and right cerebral cortex, cerebellum, midbrain, pons, medulla, and cervical spinal cord). In a similar study, phenylephrine $1 \mathrm{mg} / \mathrm{kg}$ and 10 $\mathrm{mg} / \mathrm{kg}$ were compared to epinephrine $0.2 \mathrm{mg} / \mathrm{kg}$ in 15 pigs [49]. Epinephrine was significantly better than the phenylephrine $1 \mathrm{mg} / \mathrm{kg}$ group in improving regional cerebral blood flow, however, there was no difference in regional cerebral blood flow with epinephrine, compared to the $10 \mathrm{mg} / \mathrm{kg}$ phenylephrine group.

In a similar study, the same author compared intravenous epinephrine $0.02 \mathrm{mg} / \mathrm{kg}$ and $0.2 \mathrm{mg} / \mathrm{kg}$ to intravenous methoxamine $0.1 \mathrm{mg} / \mathrm{kg}, 1 \mathrm{mg} / \mathrm{kg}$, and $10 \mathrm{mg} / \mathrm{kg}$ in pigs ( $n=5$ for each group) [25]. This study demonstrated that high dose epinephrine improved cerebral blood flow in all areas evaluated to a greater extent $(P=0.0001)$ than methoxamine. In a different study that has been previously described, methoxamine $(20 \mathrm{mg})$ demonstrated similar increases in blood flow to different areas of the brain as epinephrine $(0.2$ $\mathrm{mg} / \mathrm{kg}$ every $3 \mathrm{~min}$ ) [55].

In an another study by Brown et al. (similar protocol design as his previous studies), epinephrine $0.2 \mathrm{mg} / \mathrm{kg}$ was compared to norepinephrine 0.8 $\mathrm{mg} / \mathrm{kg}, 0.12 \mathrm{mg} / \mathrm{kg}$, and $0.16 \mathrm{mg} / \mathrm{kg}$ in pigs $(n=5$ for each group) [64]. The results showed that in general there was no statistical differences in regional cerebral blood flow between epinephrine $0.2 \mathrm{mg} / \mathrm{kg}$ and norepinephrine $0.16 \mathrm{mg} / \mathrm{kg}$ However, both these doses improved cerebral blood flow to the lower brainstem structures greater than the $0.08 \mathrm{mg} / \mathrm{kg}$ dose of norepinephrine. Epinephrine $0.2 \mathrm{mg} / \mathrm{kg}$ has also been compared to norepinephrine $0.2 \mathrm{mg} / \mathrm{kg}$ in 14 pigs [58]. No significant differences in cerebral blood flow were observed between the two groups. In another study, epinephrine $45 \mu \mathrm{g} / \mathrm{kg}$ was compared to norepinephrine $45 \mu \mathrm{g} / \mathrm{kg}$ and placebo in 21 pigs in a blinded fashion [65]. Each pig underwent $5 \mathrm{~min}$ of cardiopulmonary arrest followed by $3 \mathrm{~min}$ of open-chest cardiac massage. After 3 min of CPR, the study drugs were administered. Both epinephrine and norepinephrine significantly improved cerebral blood flow compared to the control group $(P<0.05)$. However, there was no significant difference between the epinephrine and norepinephrine groups $(54 \pm 14 \mathrm{ml} / \mathrm{min}$ per $100 \mathrm{~g}$ vs. $58 \pm 22 \mathrm{ml} / \mathrm{min}$ per $100 \mathrm{~g}$ post drug administration, respectively). Cerebral oxygen delivery also improved to a similar extent following epinephrine and norepinephrine administration $(7.4 \pm 1.7 \mathrm{ml} / \mathrm{min}$ per $100 \mathrm{~g}$ vs. $7.3 \pm 2.7 \mathrm{ml} / \mathrm{min}$ per $100 \mathrm{~g}$, respectively).

Overall, these studies suggest that epinephrine improves cerebral blood flow to a greater extent and more consistently than pure $\alpha_{1}$-agonists such as phenylephrine and methoxamine. However, higher doses of the selective $\alpha_{1}$-agonists may have effects similar to epinephrine. In contrast, it appears that norepinephrine, which lacks $\beta_{2}$-agonist properties, improves cerebral measurements to a similar degree as epinephrine. Norepinephrine may therefore prove to be equally efficacious during CPR.

\subsection{Human experience}

There are a limited number of studies comparing different vasoactive agents during ventricular fibrillation in patients due to the difficulties of performing studies in this population. In one doubleblind study, intravenous phenylephrine $1.0 \mathrm{mg}$ was compared to intravenous epinephrine $0.5 \mathrm{mg}$ in 65 patients with out-of-hospital cardiac arrests (ventricular fibrillation, asystole, electromechanical 
dissociation) [3]. Twenty-eight percent of patients were resuscitated with epinephrine compared to $31 \%$ of those in the phenylephrine group. From these results there appears to be no difference between epinephrine and phenylephrine in resuscitation rates. However, there are a number of limitations in this study which makes the conclusion questionable. One limitation is the dose of epinephrine used is probably too low to be effective which does not allow for adequate trial of the drug [4]. Another limitation of the study is that the number of patients evaluated may be too small to detect any true differences between the two groups (Type II error). Finally, equivalent pressor doses of these agents were not evaluated which makes comparison of these agents in this study difficult. Perhaps a more comparable study design would be to administer a dose of epinephrine that has been shown to improve coronary perfusion pressure and survival in animals and compare this to an equivalent pressor dose of phenylephrine.

The effects of intravenous epinephrine $0.5 \mathrm{mg}$ and methoxamine $5 \mathrm{mg}$ were evaluated in $102 \mathrm{pa}$ tients with ventricular fibrillation in a randomized double-blinded study [2]. The percentage of patients who were successfully resuscitated (defined as having a pulse and rhythm upon arrival to the emergency department) was significantly greater with epinephrine treatment as compared to methoxamine (39.2\% vs. $17.7 \%$, respectively; $P<$ 0.02 ). In addition, the percentage of patients alive after hospitalization was also greater after epinephrine administration as compared to methoxamine $(19.6 \%$ vs. $7.8 \%$, respectively; $P<$ $0.07)$. These results suggest that epinephrine is superior to methoxamine for improving resuscitation and survival in the doses studied.

A third study prospectively evaluated the effects of epinephrine $1 \mathrm{mg}$ and norepinephrine $1 \mathrm{mg}$ in 50 patients with out-of-hospital ventricular fibrillation in a randomized and blinded manner [66]. If the first dose of either epinephrine or norepinephrine failed to restore spontaneous circulation, standard guidelines for advanced cardiac life support were implemented. Resuscitation was defined as sustaining a systolic blood pressure $>80 \mathrm{mmHg}$ for $>12 \mathrm{~h}$. Initial successful resuscita- tion occurred in six of 25 patients following epinephrine and defibrillation and in 14 of 25 patients following norepinephrine and defibrillation $(P<0.05)$. In addition, the number of patients resuscitated following additional advanced life support was significantly higher in the norepinephrine group compared to the epinephrine group ( 16 of 25 vs. 8 of 25 , respectively). However, there was no difference in hospital discharge rate for norepinephrine (six of 25) or epinephrine (four of 25). Ventricular arrhythmias were observed in six of eight epinephrine and eight of 16 norepinephrine patients $60 \mathrm{~min}$ after cardiopulmonary resuscitation. In addition to the small sample size, a limitation of this study is that it is unknown if the doses of norepinephrine and epinephrine are equipotent in humans during CPR.

A final study evaluated the effect of high-dose epinephrine ( $15 \mathrm{mg}$ ), high-dose norepinephrine (11 $\mathrm{mg}$ ), or standard-dose epinephrine $(1 \mathrm{mg})$ in the initial treatment of prehospital cardiac arrest (including ventricular fibrillation, EMD, and asystole) [67]. A total of 816 patients were enrolled in this randomized, prospective, double-blind clinical trial. The results demonstrated no difference between epinephrine and norepinephrine for return of spontaneous circulation in the field, admission to hospital, hospital discharge, and Cerebral Performance Category score. However, high-dose epinephrine did have a greater percentage of patients admitted to the hospital than norepinephrine $(18 \% \quad$ vs. $13 \%$, respectively $)$ whereas norepinephrine had the highest percentage of patients discharged from the hospital $(2.6 \%$ vs. $1.7 \%$, respectively). These findings need to be evaluated with caution since the major end point, hospital discharge, probably did not have sufficient power to detect a difference since the number of patients that survived was low $(n=18)$. In addition, arrest to drug interval was long $(16 \mathrm{~min})$ which suggests that the ability for drug therapy to improve survival may have been compromised. In context of these limitations the results of this study suggest that there is no difference between epinephrine and norepinephrine in regards to the treatment of cardiac arrest. 


\section{Pulseless electrical activity (PEA)}

Pulseless electrical activity (PEA) is a situation in which there is no pulse in the presence of organized electrical activity that is expected to produce a pulse. PEA has a broad differential diagnosis, including treatable conditions (hypovolemia, tension pneumothorax, tamponade, etc.) and true electromechanical dissociation (EMD). True EMD occurs when there is a regular electrical rhythm without mechanical contraction of heart muscle, no mechanical systole, and therefore no pulse. The likelihood of survival in patients with true EMD or PEA without a treatable condition is considered poor. In the treatment of PEA, epinephrine is currently considered first line therapy. There are a limited number of studies comparing epinephrine to other adrenergic agonists during PEA.

Epinephrine and methoxamine were compared in 80 patients with EMD in a prospective, randomized, double-blinded study [68]. Epinephrine 1 $\mathrm{mg}$ or methoxamine $10 \mathrm{mg}$ were administered intravenously according to the ACLS algorithm [1]. Twenty-two patients receiving methoxamine and 22 patients receiving epinephrine survived less than one hour, 15 patients receiving methoxamine and 13 patients receiving epinephrine survived 1-6 $h$, three patients receiving methoxamine and two patients receiving epinephrine survived more than $24 \mathrm{~h}$ but not to discharge, and only one patient receiving epinephrine survived to discharge. From these results it appears that there is no difference between epinephrine and methoxamine for improving survival post EMD. The extremely poor survival illustrates the prognosis of true EMD and the importance of seeking and correcting the other causes of PEA.

\section{Conclusions}

Overall, from the data presented, it appears that phenylephrine and methoxamine offer no advantage in improving survival, coronary perfusion pressure, cerebral blood flow, or myocardial oxygen demand compared to epinephrine. There are data to suggest that epinephrine may even be supe- rior to these agents. However, species-dependent effects may be a consideration with these drugs. According to the limited data available from animal and human studies, norepinephrine and epinephrine appear to have similar efficacy in the treatment of ventricular fibrillation. Further studies are needed to determine if the absence of $\beta_{2}$ adrenergic activity with norepinephrine is beneficial compared to epinephrine. Until further studies are performed (specifically, in humans), epinephrine remains the adrenergic agonist of choice in the treatment of ventricular fibrillation and PEA.

\section{References}

[1] Emergency cardiac care committee and subcommittees, American Heart Association. Guidelines for cardiopulmonary resuscitation and emergency cardiac care. J Am Med Assoc 1992; 268: 2199-2241.

[2] Olsen DW, Thakur R, Stueven HA et al. Randomized study of epinephrine versus methoxamine in prehospital ventricular fibrillation. Ann Emerg Med 1989; 18: 250-253.

[3] Silfvast T, Saarnivaara I, Kinnunen A et al. Comparison of adrenaline and phenylephrine in out-of-hospital cardiopulmonary resuscitation: a double-blind study. Acta Anaesthesiol Scand 1985; 29: 610-613.

[4] Paradis NA, Koscove EM. Epinephrine in cardiac arrest: a critical review. Ann Emerg Med 1990; 19: 1288-1301.

[5] Milnor WR, Stone DN, Sastre A. Contributions of $\alpha_{1}$ and $\alpha_{2}$-adrenoceptors to contractile response in canine blood vessels ${ }^{1}$. Blood Vessels 1988; 25: 199-208.

[6] Gilman AG, Goodman LS, Gilman A. The pharmacological basis of therapeutics, 6th ed. New York: Macmillan Publishing Co. Inc.; 1980.

[7] Paradis NA, Martin GB, Rivers EP et al. Coronary perfusion pressure and the return of spontaneous circulation in human cardiopulmonary resuscitation. J Am Med Assoc 1990; 263: 1106-1113.

[8] Sanders AB, Ewy GA, Taft TV. Prognostic and therapeutics importance of the aortic diastolic pressure in resuscitation from cardiac arrest. Crit Care Med 1984; 12: 871-873.

[9] Niemann JT, Criley JM, Rosborough JP et al. Predictive indices of successful cardiac resuscitation after prolonged arrest and experimental cardiopulmonary resuscitation. Ann Emerg Med 1985; 14: 521-528.

[10] Ditchey RV, Winkler JV, Rhodes CA. Relative lack of coronary blood flow during closed-chest resuscitation in dogs. Circulation 1982; 66(2): 297-302.

[11] Niemann JT, Rosborough JP, Ung S et al. Coronary per- 
fusion pressure during experimental cardiopulmonary resuscitation. Ann Emerg Med 1982; 11: 1127-1131.

[12] Yakaitis RW, Otto CW, Blitt CD. Relative Importance of $\alpha$ and $\beta$ adrenergic receptors during resuscitation. Crit Care Med 1979; 7: 293-296.

[13] Michael JR, Guerci AD, Koehler RC et al. Mechanisms by which epinephrine augments cerebral and myocardial perfusion during cardiopulmonary resuscitation in dogs. Circulation 1984; 69: 822-835.

[14] Koehler RC, Michael JR, Guerci AD et al. Beneficial effect of epinephrine infusion on cerebral and myocardial blood flows during CPR. Ann Emerg Med 1985; 14: 744-749.

[15] Kobinger $\mathbf{W}$, Pichler $\mathbf{L}$. $a_{1}$ - and $a_{2}$-adrenoceptor subtypes: selectivity of various agonists and relative distribution of receptors as determined in rats. Eur J Pharmacol 1981; 73: 313-321.

[16] Brown CG, Katz SE, Werman HA et al. The effect of epinephrine versus methoxamine on regional myocardial blood flow and defibrillation rates following a prolonged cardiorespiratory arrest in a swine model. Am J Emerg Med 1987; 5: 362-369.

[17] Brown CG, Taylor RB, Werman HA et al. Myocardial oxygen delivery/consumption during cardiopulmonary resuscitation: a comparison of epinephrine and phenylephrine. Ann Emerg Med 1988; 17: 302-308.

[18] Langer SZ, Massingham R, Shepperson NB. Presence of Postsynaptic $a_{2}$-Adrenoreceptors of predominantly extrasynaptic location in the vascular smooth muscle of the dog hind limb. Clin Sci 1980; 59: 225s-228s.

[19] Langer SZ, Shepperson NB. Postjunctional $a_{1}-$ and $a_{2}$-adrenoceptors: perferential innervation of $a_{1}$ adrenoceptors and the role of neuronal uptake. J Cardiovasc Pharmacol 1982; 4: S8-S13.

[20] Robinson LA, Brown CG, Jenkins $J$ et al. The effect of norepinephrine versus epinephrine on myocardial hemodynamics during CPR. Ann Emerg Med 1989; 18: 336-340.

[21] Watanabe Y, Lai RT, Yoshida H. Increase of $\left[{ }^{3} \mathrm{H}\right]$ clonidine binding sites induced by adenosine receptor agonists in rat vas deferens in vitro. Eur $\mathrm{J}$ Pharmcol 1983; 86: 265-269.

[22] Mukherjee A, Bush LR, McCoy KE et al. Relationship between b-adrenergic receptor numbers and physiological responses during experimental canine myocardial ischemia. Circ Res 1982; 50: 735-741.

[23] Ruffy R, Schechtman K, Monje E. b-adrenergic modulation of direct defibrillation energy in anesthetized dog heart. Am J Physiol 1985; 248: H674-H677.

[24] Ruffy R, Schechtman K, Monje E et al. Adrenergically mediated variations in the energy required to defibrillate the heart: observations in closed-chest, nonanesthetized dogs. Circulation 1986; 73(2): 374-380.

[25] Brown CG, Davis EA, Werman HA et al. Methoxamine versus epinephrine on regional cerebral blood flow during cardiopulmonary resuscitation. Crit Care Med 1987; 15: $682-686$
[26] LaCombe EL, Owman P, Reynier-Rebuffel $\mathrm{CH}$ et al. Quantitative changes in regional cerebral blood flow of rats induced by alpha- and beta-adrenergic stimulants. Acta Physiol Scand 1979; 107: 289-296.

[27] Neumar RW, Brown CG, Van Ligten $P$ et al. Estimation of myocardial ischemic injury during ventricular fibrillation with total circulatory arrest using high-energy phosphates and lactate as metabolic markers. Ann Emerg Med 1991; 20: 222-229.

[28] Kern KB, Garewal HS, Sanders AB et al. Depletion of myocardial adenosine triphosphate during prolonged untreated ventricular fibrillation: effect on defibrillation sucess. Resuscitation 1990; 20: 221-229.

[29] Ditchey RV, Lindenfeld J. Failure of epinephrine to improve the balance between myocardial oxygen supply and demand during closed-chest resuscitation in dogs. Circulation 1988; 78: 382-389.

[30] Hoekstra JW, Griffith R, Kelley $R$ et al. Effect of standard-dose versus high-dose epinephrine on myocardial high-energy phosphates during ventricular fibrillation and closed-chest CPR. Ann Emerg Med 1993; 22: 1385-1391.

[31] Ditchey RV, Slinker BK. Phenylephrine plus propranolol improves the balance between myocardial oxygen supply and demand during experimental cardiopulmonary resuscitation. Am Heart J 1994; 127: 324-330.

[32] Neumar RW, Brown CG, Robitaille PML et al. Myocardial high energy phosphate metabolism during ventricular fibrillation with total circulatory arrest. Resuscitation 1990; 19: 199-226.

[33] Hori M, Kitakaze M. Adenosine, the heart, and coronary circulation. Hypertension 1991; 18: 565-574.

[34] Clarke B, Coupe M. Adenosine: cellular mechanisms, pathophysiological roles and clinical applications. Int $\mathbf{J}$ Cardiol 1989; 23: 1-10.

[35] Van Calker D, Muller M, Hamprecht B. Adenosine regulates via two different types of receptors the accumulation of cyclic AMP in cultured brain cells. J Neurochem 1979; 33: 999-1005.

[36] Belardinelli L, Isenberg G. Actions of adenosine and isoproterenol on isolated mammalian ventricular myocytes. Circ Res 1983; 53: 287-297.

[37] Isenberg G, Belardinelli L. Ionic basis for the antagonism between adenosine and isoprterenol on isolated mammalian ventricular myocytes. Circ Res 1984; 55: 309-325.

[38] Ely SW, Mentzer RM, Lasley RD et al. Functional and metabolic evidence of enhanced myocardial tolerance to ischemia and reperfusion with adenosine. J Thorac Cardiovasc Surg 1985; 90: 549-556.

[39] Cronstein BN, Levin RI, Belanoff J et al. Adenosine: an endogenous inhibitor of neutrophil-mediated injury to endothelial cells. J Clin Invest 1986; 78: 760-770.

[40] Roberts PA, Newby AC, Hallett MB et al. Inhibition by adenosine of reactive oxygen metabolite production by human polymorphonuclear leukocytes. Biochem J 1985; 227: 669-674. 
[41] von Planta M, von Planta I, Wagner O et al. Adenosine during cardiac arrest and cardiopulmonary resuscitation: a placebo-controlled, randomized trial. Crit Care Med 1992; 20: 645-649.

[42] Kitakaze M, Hori $M$, Tamai J et al. a tivity regulates release of adenosine from the ischemic myocardium in dogs. Circ Res 1987; 60: 631-639.

[43] Hori $M$, Kitakaze $M$, Tamai $J$ et al. Alpha $2_{-}^{-}$ adrenoceptor activity exerts dual control of coronary blood flow in canine coronary artery. Am J Physiol 1988; 255: $\mathrm{H} 250-\mathrm{H} 260$.

[44] Kitakaze $M$, Hori $M$, Gotoh $K$ et al. Beneficial effects of $\alpha_{2}$-activity on ischemic myocardium during coronary hypoperfusion in dogs. Circ Res 1989; 65: 1632-1645.

[45] Hori $M$, Kitakaze $M$, Tamai $J$ et al. Alpha adrenoceptor stimulation can augment coronary vasodilatation maximally induced by adenosine in dogs. Am J Physiol 1989; 257: H132-H140.

[46] Redding JS, Pearson JW. Resuscitation from ventricular fibrillation. J Am Med Assoc 1968; 204: 93-98.

[47] Pearson JW, Redding JS. Peripheral vascular tone on cardiac resuscitation. Anaesthes Analg 1965; 44: 746-752.

[48] Brillman J, Sanders A, Otto CW et al. Comparison of epinephrine and phenylephrine for resuscitation and neurologic outcome of cardiac arrest in dogs. Ann Emerg Med 1987; 16: 11-17.

[49] Brown CG, Werman HA, Davis EA et al. The effect of high-dose phenylephrine versus epinephrine on regional cerebral blood flow during CPR. Ann Emerg Med 1987; 16: 743-748.

[50] Brown CG, Birinyi F, Werman HA et al. The comparative effects of epinephrine versus phenylephrine on regional cerebral blood flow during cardiopulmonary resuscitation. Resuscitation 1986; 14: 171-183.

[51] Howe BB, Fehn PA, Pensinger RR. Comparative anatomical studies of the coronary arteries of canine and porcine hearts free ventricle wall. Acta Anat 1968; 71 : 12-21.

[52] Bowman TA, Hughes HC. Swine as an in vivo model for electrophysiologic evaluation of cardiac pacing parameters. PACE Pacing Clin Electrophysiol 1984; 7 : 187.

[53] Schafer W, Jageneau A, Xhonneux R. The development of collateral circulation in the pig and dog heart. Cardiologia 1967; 51: 321-335.

[54] Angus JA, Cocks TM, Satoh K. The $\alpha$ adrenoceptors on endothelial cell. Fed Proc 1986; 45: 2355-2359.

[55] Roberts D, Landolfo K, Dobson $K$ et al. The effects of methoxamine and epinephrine on survival and regional distibution of cardiac output in dogs with prolonged ventricular fibrillation. Chest 1990; 98: 999-1005.
[56] Bleske BE, Chow MSS, Zhoa $\mathrm{H}$ et al. Epinephrine versus methoxamine in survival postventricular fibrillation and cardiopulmonary resuscitation in dogs. Crit Care Med 1989; 17: 1310-1313.

[57] Lindner KH, Ahnefeld FW. Comparison of epinephrine and norepinephrine in the treatment of asphyxial or fibrillatory cardiac arrest in a porcine model. Crit Care Med 1989; 17: 437-441.

[58] Hoekstra JW, Van Ligten P, Neumar R et al. Effect of high dose norepinephrine versus epinephrine on cerebral and myocardial blood flow during CPR. Resuscitation 1990; 19: 227-240.

[59] Lindner KH, Ahnefeld FW, Schuermann W et al. Epinephrine and norepinephrine in cardiopulmonary resuscitation. Chest 1990; 97: 1458-1462.

[60] Midei MG, Sugiura S, Maughan WL et al. Preservation of ventricular function by treatment of ventricular fibrillation with phenylephrine. J Am Coll Cardiol 1990; 16: 489-494.

[61] Livesay JJ, Follette DM, Fey KH et al. Optimizing myocardial supply/demand balance with a-adrenergic drugs during cardiopulmonary resuscitation. J Thorac Cardiovasc Surg 1978; 76: 244-251.

[62] Kern KB, Ewy Ga. Minimal coronary stenoses and left ventricular blood flow during CPR. Ann Emerg Med 1992; 21: 1066-1072.

[63] Ditchey RV, Horwitz LD. Metabolic evidence of inadequate coronary blood flow during closed-chest resuscitation in dogs. Cardiovasc Res 1985; 19: 419-425.

[64] Brown CG, Robinson LA, Jenkins J et al. The effect of norepinephrine versus epinephrine on regional cerebral blood flow during cardiopulmonary resuscitation. Am J Emerg Med 1989; 7: 278-282.

[65] Lindner KH, Ahnefeld FW, Plenninger EG et al. Effects of epinephrine and norepinephrine on cerebral oxygen delivery and consumption during open-chest CPR. Ann Emerg Med 1990; 19: 249-254.

[66] Lindner KH, Ahnefeld FW, Grunert A. Epinephrine versus norepinephrine in prehospital ventricular fibrillation. Am J Cardiol 1991; 67: 427-428.

[67] Callaham M, Madsen CD, Barton CW et al. A randomized clinical trial of high-dose epinephrine and norepinephrine vs. standard-dose epinephrine in prehospital cardiac arrest. J Am Med Assoc 1992; 268: 2667-2672.

[68] Turner LM, Parson M, Leuikemeyer RC et al. A comparison of epinephrine and methoxamine for resuscitation from electromechanical dissociation in human beings. Ann Emerg Med 1988; 17: 443-449. 